\title{
COMBINED ETHANOL EXTRACT OF FUNTUMIA AFRICANA AND ABUTILON MAURITIANIUM LEAVES IMPROVES THE LIPID PROFILE AND KIDNEY FUNCTION INDICES OF BENIGN PROSTATIC HYPERPLASIA IN RATS
}

\author{
Robert I. Uroko ${ }^{1}$, Charles N. Chukwu ${ }^{1 凶}$, Simeon I. Egba ${ }^{1}$, Fatima A. Adamude ${ }^{2}$, \\ Joy C. Ajuzie ${ }^{1}$
}

${ }^{1}$ Department of Biochemistry, College of Natural Sciences, Michael Okpara University of Agriculture Umudike, P.M.B. 7267, Umuahia, Abia State, Nigeria

${ }^{2}$ Department of Biochemistry, Faculty of Medical Sciences, Federal University Lafia Nasarawa State, Nigeria W/L 05 Wizy Lodge, Umuaroko Road, Ahiaeke, 440233 Umuahia, Abia State, Nigeria

\begin{abstract}
Background. Benign prostate hyperplasia $(\mathrm{BPH})$ is a non-cancerous enlargement of the prostate gland as a result of an overgrowth of prostate cells and muscles found around the prostatic transition. It is age-dependent and characterized by benign prostate enlargement (BPE), bladder outlet obstruction (BOO) and lower urinary tract symptoms (LUTS). The study investigated the effects of a combined extract of Funtumia africana and Abutilon mauritianum leaves (CEFA) on the lipid profile and renal indices of testosterone-induced BPH in male albino rats.

Materials and methods. Thirty (30) male albino rats ( $100-150 \mathrm{~g})$ divided into 5 groups $(n=6)$ were used. BPH was induced subcutaneously with $2 \mathrm{ml}$ of testosterone propionate. Groups 1-3 served as normal, BPH untreated and standard drug controls respectively, while groups 4 and 5 were BPH-induced and treated with low $(200 \mathrm{mg} / \mathrm{kg})$ and high $(600 \mathrm{mg} / \mathrm{kg})$ doses of CEFA respectively. After twenty-eight days of treatment, the rats were anaesthetized, blood was collected by cardiac puncture and the sera centrifuged to determine lipid profile and renal indices using standard analytical procedures.

Results. The acute toxicity result of CEFA indicated no mortality or adverse reactions. The results of the lipid profile and renal function studies showed a significant $(p<0.05)$ increase in triacylglycerol (TAG), total cholesterol (TC), urea and creatinine, and a significant $(p<0.05)$ decrease in high-density lipoprotein (HDL) concentrations in the BPH control group when compared to the normal control. Treatment with CEFA caused a significant $(p<0.05)$ decrease in TAG, urea and creatinine concentrations and a significant $(p<0.05)$ increase in HDL-C when compared to the untreated group. No significant $(p>0.05)$ difference was observed in serum concentrations of TC and low-density lipoprotein (LDL) in the treatment groups compared to the BPH control. The histopathological result indicated no toxic insult on the kidney tissues.

Conclusion. The findings suggest that CEFA possesses antilipidaemic properties in terms of elevation and decrease in HDL and TAG concentrations respectively. Also, CEFA possesses renoprotective potential in terms of reducing urea and creatinine concentrations.
\end{abstract}

Keywords: antilipidaemia, renoprotective, Funtumia africana, Abutilon mauritianum, benign prostatic hyperplasia 


\section{INTRODUCTION}

Benign prostatic hyperplasia $(\mathrm{BPH})$ is a histologic condition characterized by proliferation of tissues of the epithelial glands, smooth muscle, and connective tissues found around the prostatic transition zone. BPH is pervasive in the ageing male with its pervasiveness growing with age (Foster et al., 2018; Parsons and Kashefi, 2008). Benign prostatic hyperplasia - BPH is mainly characterized by benign prostate enlargement (BPE), together with bladder outlet obstruction (BOO) and lower urinary tract symptoms (LUTS) (Wu et al., 2017).

Benign prostatic hyperplasia - $\mathrm{BPH}$ is mainly managed by surgery or use of orthodox drugs including alpha-adrenergic blocking agents, 5-alpha reductase inhibitors or a combination of both (de Souza et al., 2011). However, despite the temporary relief offered by these drugs, they are usually associated with reoccurrence and/or some side effects including faintness, erectile dysfunction, diminished libido, and reduced ejaculate volume and in uncommon circumstances breast enlargement or soreness (Naslund et al., 2007; American Urological Association, 2003).

Conflicting studies about the biologic effects of serum lipid levels on the prostate have been reported. According to Lekili et al. (2006), high serum lipid levels may portend BPH and lowering high serum lipid levels may prove important in averting the advancement of BPH and also decrease the need for surgery. Likewise, higher serum LDL was reported to increase the risk of BPH among diabetics (Parsons et al., 2008). On the other hand, no correlations of serum lipids with International Prostate Symptom Score or prostate volume were reported (Gupta et al., 2006; Lekili et al., 2006; Zucchetto et al., 2005). A positive and significant cross-sectional relationship between $\mathrm{BOO}$ and chronic kidney disease in community-dwelling men has been reported with a characteristic elevated serum creatinine level (Rule et al., 2005). Furthermore, Asuk and Ugwu (2018) and Weinstein et al. (2009) reported alterations in urea and creatinine levels in cases of $\mathrm{BPH}$, and they could be used as a tool to measure the risk of BPH (Chiong et al., 2005).

More attention has been channeled towards phytotherapeutics in terms of providing a more effective and safer treatment strategy for patients with $\mathrm{BPH}$, with many plants showing significant anti-BPH effects (Sharma et al., 2017), including aqueous extracts of Metapanax delavayi (Sun et al., 2020) and Yongdamsagan-tang (Park et al., 2016).

Combining herbs is the use of two or more herbs in a therapeutic preparation (Parasuraman et al., 2014). It is a vital model, as herbal medicine often necessitates the mixture of a number of herbs in a thoughtful, rational and systematic way. Combined herbs are used in the treatment of many diseases (Aslam et al., 2016). Combining herbs is known to express high effectiveness in treating a vast number of diseases compared to a single herbal formulation. As previously mentioned, the therapeutic effects of herbal medicines are exerted due to the presence of different phytochemical constituents and the effects are further potentiated when compatible herbals are formulated together.

Funtumia africana (Benth.) Stapf (Family = Apocynaceae) is native to and commonly distributed throughout eastern, central and western Africa; the species is likewise found in certain southern African countries like Mozambique (Beentje et al., 1994; Orwa et al., 2009). In West Africa, F. africana is found to be useful in the management of fever soreness, malaria, malignancy, amoebic dysentery, urinary incontinence and burns (Ashidi et al., 2010; Odugbemi et al., 2007). Because of the presence of a range of medically active compounds in Abutilon mauritianum, like saponins, flavonoids, tannins and alkaloids, the plant parts are widely used in traditional African medicine. The leaves possess antibacterial and antimicrobial properties, while the bark is diuretic and used in the treatment of diarrhoea, stomach-ache, parasitic infections, venereal diseases, malaria, coughs and colds (Burkill, 2004; Cowan, 2000).

These phytoconstituents of Funtumia africana and Abutilon mauritianum, as seen in other plants, have been shown to possess inhibitory effects against 5-alpha reductase, anti-inflammatory and free radical scavenging activities, modulatory effects on prolactininduced prostatic growth and protective effects on bladder and detrusor function (Sharma et al., 2017).

Funtumia africana and Abutilon mauritianum have over the years proven to be very important plants in traditional medicine and are found almost everywhere as they adapt easily to various environmental conditions. Hence, this study was aimed at evaluating the 

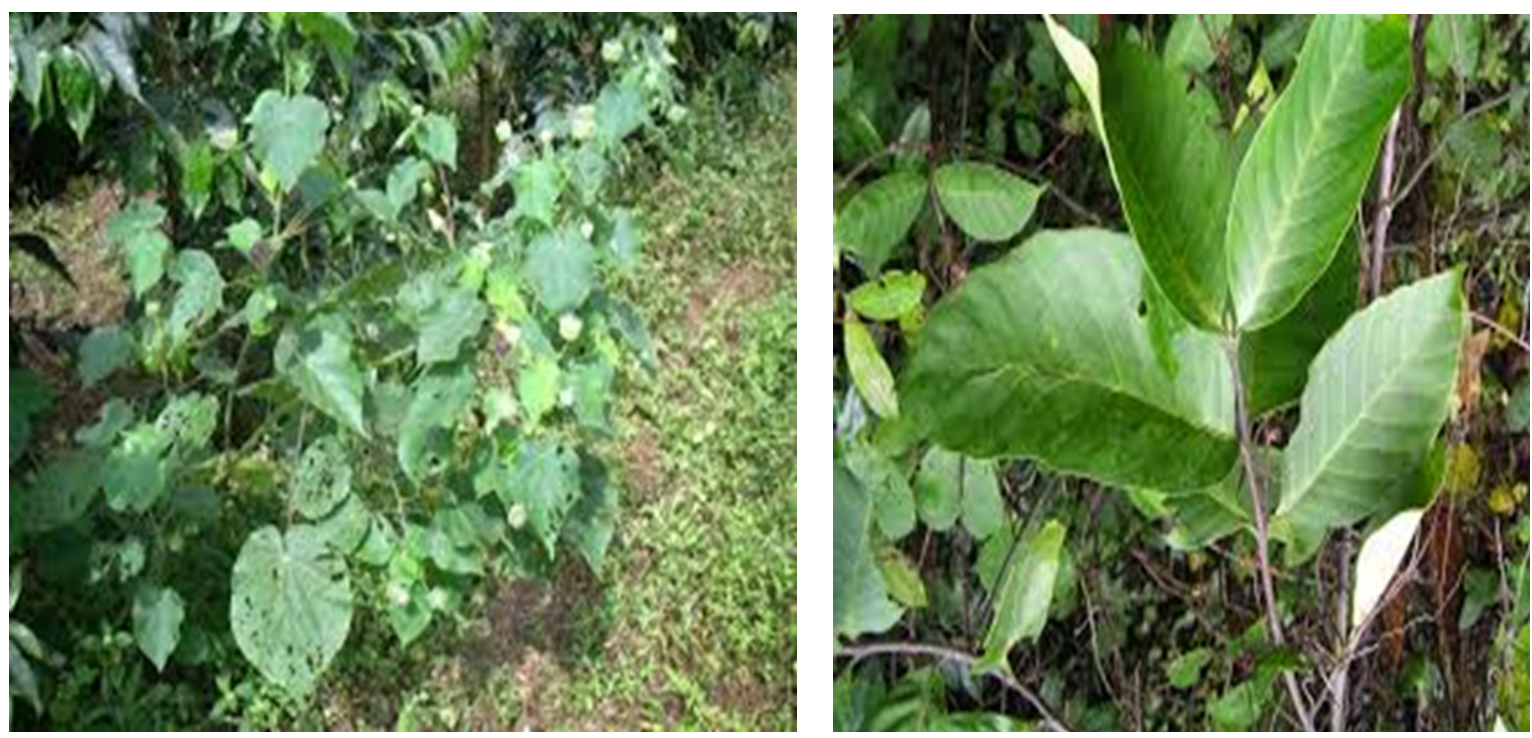

Fig. 1. Funtumia africana (A) and Abutilon mauritianum (B) leaves

effects of the combined extract of $F$. africana and A. mauritianum leaves on the lipid profile and kidney function indices of testosterone-induced benign prostatic hyperplasia in rats.

\section{MATERIALS AND METHODS}

\section{Collection, identification and preparation of plant materials}

Fresh leaves of $F$. africana and A. mauritianum were collected from a farm located in the Michael Okpara University of Agriculture, Umudike (MOUAU), Abia State, Nigeria in June, 2019 and authenticated in the Department of Forestry, MOUAU. These plant materials were thoroughly cleaned, washed with tap water and dried at room temperature. The dried samples were pulverized into a coarse powder using an electric blender. At a ratio of 1:1 (i.e. $250 \mathrm{mg}$ of coarsely ground sample each equivalent to $500 \mathrm{~g}$ of both plant samples), the combined sample was soaked in $1.5 \mathrm{~L}$ of absolute ethanol for 72 hours. The extracted material was filtered with a muslin cloth and thereafter with Whatman No 1 filter paper. The filtrate obtained was concentrated till the ethanol solvent completely evaporated in a water bath at $65^{\circ} \mathrm{C}$ and the percentage yield determined.

\section{Collection and acclimatization of experimental animals}

Thirty (30) male albino rats weighing 100-150 g were purchased from the Animal House of the Department of Zoology and Environment Sciences, Faculty of Biological Sciences, University of Nigeria Nsukka, Nigeria and housed at the Animal House of the Department of Biochemistry, College of Natural Sciences, MOUAU for 7 days under twelve hours dark and light cycle with access to standard animal feed (Vital Feeds) and water ad libitum. On approval by the Research Ethics Board of the Department of Biochemistry, the animals were handled in adherence with the National Institute of Health's guidelines for the care and use of Laboratory animals (Institute of Laboratory Animal Resources, 1986).

\section{Experimental design}

After acclimatization, the rats were distributed into 5 groups containing 6 rats each. Group 1 was made up of normal rats that received only animal fed and $1 \mathrm{~mL} / \mathrm{kg}$ of distilled water and olive oil in the ratio of 1:1 (v/v). Group 2 was the BPH control that was BPH-induced but untreated, while group 3 was the standard control that was BPH-induced and treated with $0.8 \mathrm{mg} / \mathrm{kg} / \mathrm{day}$ of finasteride. Groups 4 and 5 were 
made up of BPH-induced rats treated with 200 and $600 \mathrm{mg} / \mathrm{kg}$ of combined ethanol extract of Funtumia africana and Abutilon mauritianum leaves respectively according to their respective body weights. Benign prostatic hyperplasia - BPH was induced in the rats by subcutaneous injection of testosterone propionate mixed with olive oil at a ratio of $1: 1(\mathrm{v} / \mathrm{v} ; 3 \mathrm{mg} / \mathrm{kg}$ body weight) for 28 consecutive days. The combined extracts and finasteride respectively were administered orally 1 hour after the testosterone propionate (TP) injection for the 28 consecutive days. After the last day of administration of testosterone propionate and treatments on the 28th day, the rats were placed on a fast overnight and blood samples and kidney tissues were collected from the animals for biochemical analyses and histological examination respectively.

\section{Acute toxicity $\left(\mathrm{LD}_{50}\right)$ of the plant}

The acute toxicity test was conducted on the leaves in two phases in accord with Lorke's method (Lorke, 1983).

\section{Determination of lipid profile}

The total cholesterol and high-density lipoprotein (HDL) concentrations of the serum were determined spectrophotometrically using the method of Allain et al. (1974) and Albers et al. (1978) respectively as contained in the procedures stated in the respective QCA commercial kits. The triacylglycerol (TAG) concentration of the serum was determined according to the method of Albers et al. (1978) as contained in Randox commercial kit, whereas the serum low-density lipoprotein cholesterol (LDL) and very low-density lipoprotein cholesterol (VLDL) concentrations were calculated using the Friedelwald equation (Friedelwald et al., 1972).

\section{Determination of serum urea and creatinine concentrations}

The urea concentration of the serum was determined using urease Berthelot according to the method described by Fawcett and Scott (1960) as outlined in Randox commercial kit, while the creatinine concentration was determined using direct endpoint according to the method of Henry (1974) as described in Randox commercial kit.

\section{Histopathological examination}

Tissue preparation. The kidneys were fixed in $10 \%$ phosphate-buffered formalin for 48 hours before tissue preparation. The tissues were clipped afterwards, dehydrated in 4 ascending grades of alcohol $(70 \%$, $80 \%, 90 \%$ and $100 \%$ ), cleared in 3 grades of xylene and embedded in molten wax. After embedding, the tissue-containing wax blocks were cut into $5 \mu \mathrm{m}$ thick sections with a rotary microtome, floated in a water bath at $60^{\circ} \mathrm{C}$, placed on clean grease-free glass slides and placed on a slide warmer set at $60^{\circ} \mathrm{C}$ overnight. Afterwards, the $5 \mu \mathrm{m}$ thick sectioned tissues on glass slides were cleared in 3 grades of xylene and rehydrated in 3 descending grades of alcohol (90,80 and 70\%). The sections were then stained with Mayer's hematoxylin for 5 minutes. Blueing was done with ammonium chloride. Differentiation was done with $1 \%$ acid alcohol before counterstaining with Eosin. Permanent mounts were made on degreased glass slides using a mountant.

Slide examination. The prepared slides were inspected using a Motic ${ }^{\mathrm{TM}}$ compound light microscope with $\times 4, \times 10$ and $\times 40$ objective lenses. The photomicrographs were taken using a Motic ${ }^{\mathrm{TM}} 5.0$ megapixel microscope camera at $\times 100, \times 160$ and $\times 400$ magnifications.

\section{Statistical analysis}

The data obtained were statistically analysed using One-way Analysis of Variance (ANOVA) with the aid of Statistical Product and Service Solutions (SPSS) version 22. The means were compared using Duncan multiple range tests and significance was established at $p<0.05$.

\section{RESULTS AND DISCUSSION}

\section{Percentage yield}

After filtration and concentration, the concentrated combined extract gave a total yield of $22.7 \%(26.06 \mathrm{~g})$.

\section{Acute toxicity result}

The acute toxicity test results of the combined ethanol extract of $F$. africana and A. mauritianum leaves on male albino rats showed no death or adverse reactions in the rats. 


\section{Lipid profile results}

Figure 2 showed that the TAG concentration in BPH-induced control rats was significantly $(p<0.05)$ higher when compared with the TAG concentration of the normal control rats and treatment groups (200 and 600 $\mathrm{mg} / \mathrm{kg}$ b.w. of CEFA). However, the TAG concentrations in the standard control and groups treated with 200 and $600 \mathrm{mg} / \mathrm{kg}$ of CEFA showed no significant $(p>0.05)$ difference in the TAG concentration relative to the normal control. Also, the standard control rats that received Finasteride and BPH-induced rats treated with low $(200 \mathrm{mg} / \mathrm{kg})$ and high doses $(600 \mathrm{mg} /$ $\mathrm{kg})$ of CEFA showed a significant $(p<0.05)$ decrease in their TAG concentrations when compared with the $\mathrm{BPH}$ control that was not treated. The result in Figure 3 showed that the HDL concentration in the BPH-induced rats was significantly $(p<0.05)$ lower when compared with the $\mathrm{NC}$, standard control and treatment groups (200 and $600 \mathrm{mg} / \mathrm{kg}$ of CEFA). There was no significant $(p>0.05)$ difference in HDL-C among the normal control, standard control and combined extract $(200$ and $600 \mathrm{mg} / \mathrm{kg}$ ) treatment groups.

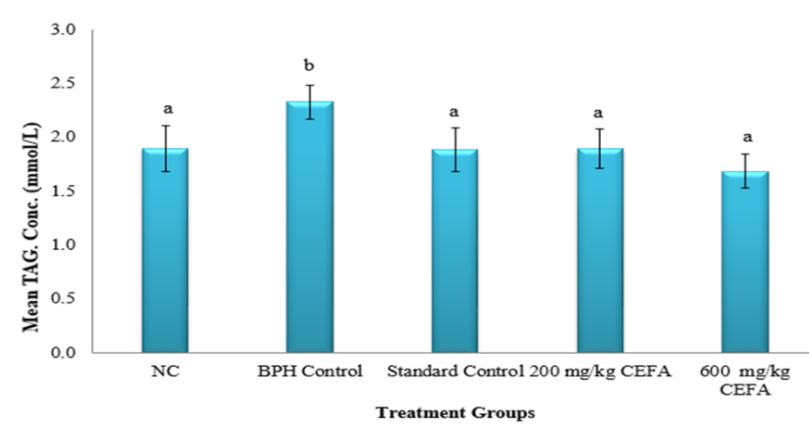

Fig. 2. Triacylglycerol (TAG) concentrations of BPH-induced rats treated with combined extracts of $F$. africana and A. mauritianum leaves (CEFA): $\mathrm{NC}$ - normal control, CEFA - combined extract of $F$. africana and A. mauritianum leaves. Each bar depicts means \pm standard deviation $(n=6)$. Bars with differing superscripts are significantly different $(p<0.05)$

From Figure 4, the TC concentration in the $\mathrm{BPH}$ control rats was significantly $(p<0.05)$ elevated when compared with the normal control rats. However, the TC concentration in standard control and groups treated with 200 and $600 \mathrm{mg} / \mathrm{kg}$ of CEFA showed no

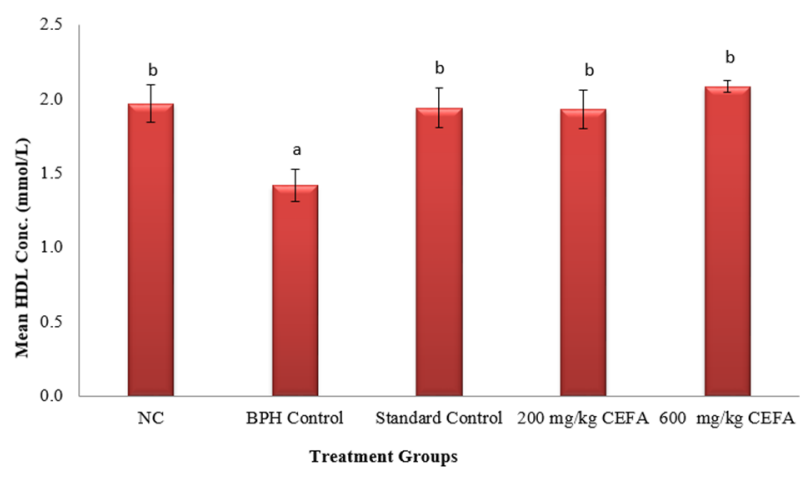

Fig. 3. High-density lipoprotein (HDL) concentrations of $\mathrm{BPH}$-induced rats treated with CEFA: $\mathrm{NC}$ - normal control, CEFA - combined extract of $F$. africana and A. mauritianum leaves. Each bar depicts the means \pm standard deviation $(n=6)$. Bars with differing superscripts are significantly different $(p<0.05)$

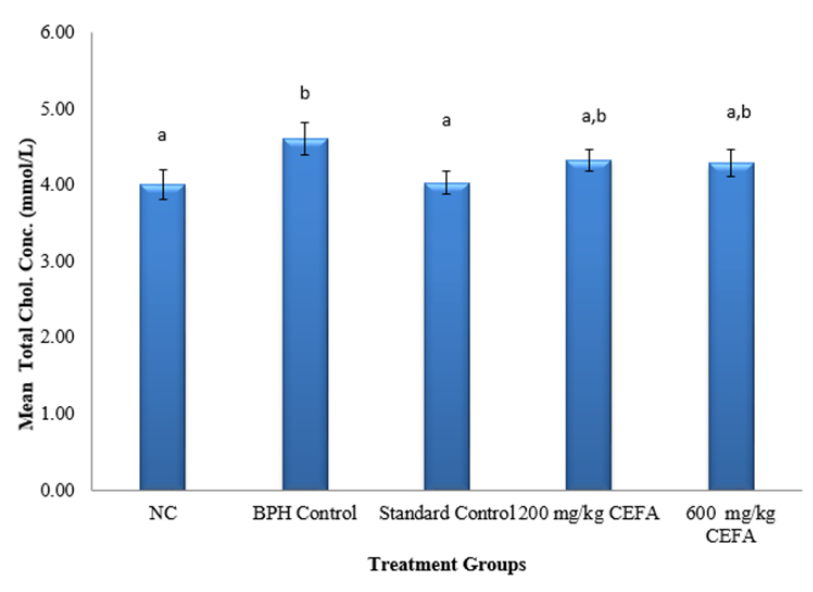

Fig. 4. Total cholesterol (TC) concentrations of BPH-induced rats treated with CEFA leaves: $\mathrm{NC}$ - normal control, CEFA - combined extract of $F$. africana and A. mauritianum leaves. Each bar depicts the means \pm standard deviation $(n=$ $6)$. Bars with differing superscripts are significantly different $(P<0.05)$

significant $(p<0.05)$ differences when compared with the NC. Also, there was no significant $(p>0.05)$ difference in TC concentration of the standard control and BPH-induced rats treated with low $(200 \mathrm{mg} / \mathrm{kg})$ and high doses $(600 \mathrm{mg} / \mathrm{kg})$ of CEFA leaves. Figure 5 showed that LDL-C in the BPH control rats was higher, although not significantly $(p>0.05)$, 


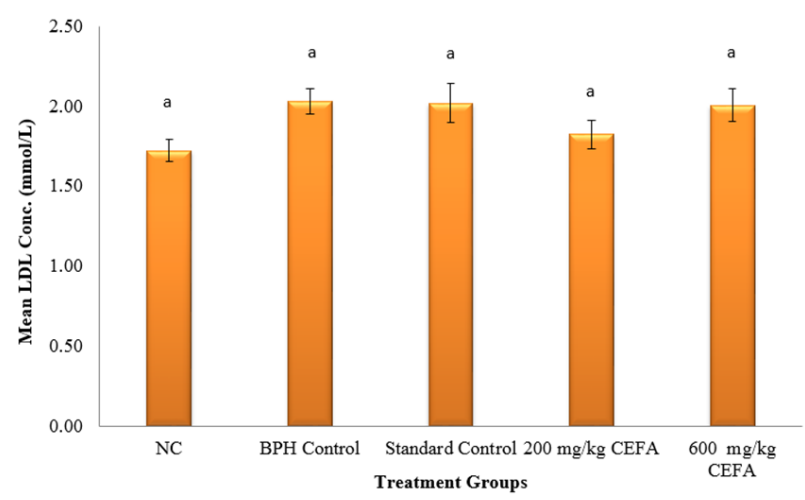

Fig. 5. Low-density lipoprotein (LDL) concentrations of $\mathrm{BPH}$-induced rats treated with CEFA: $\mathrm{NC}$ - normal control, CEFA - combined extract of F. africana and A. mauritianum leaves. Each bar depicts the means \pm standard deviation $(n=$ 6). Bars with differing superscripts are significantly different $(P<0.05)$

when compared with the $\mathrm{NC}$, standard control and CEFA groups. Furthermore, there was an insignificant $(p>0.05)$ difference in the LDL concentration among the other groups.

\section{Kidney function indices}

Figure 6 shows the effects of the combined extract of $F$. africana and $A$. mauritianum leaves (CEFA) on urea concentration in $\mathrm{BPH}$-induced albino rats. The urea

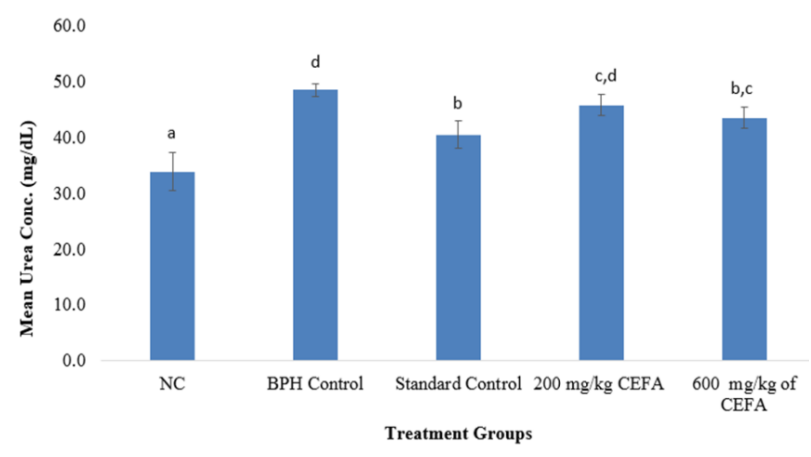

Fig. 6. Urea concentrations of BPH-induced rats treated with combined extract of $F$. africana and $A$. mauritianum leaves: NC - normal control, CEFA - combined extract of F. africana and A. mauritianum leaves. Each bar depicts the means \pm standard deviation $(n=6)$. Bars with differing superscripts are significantly different $(P<0.05)$

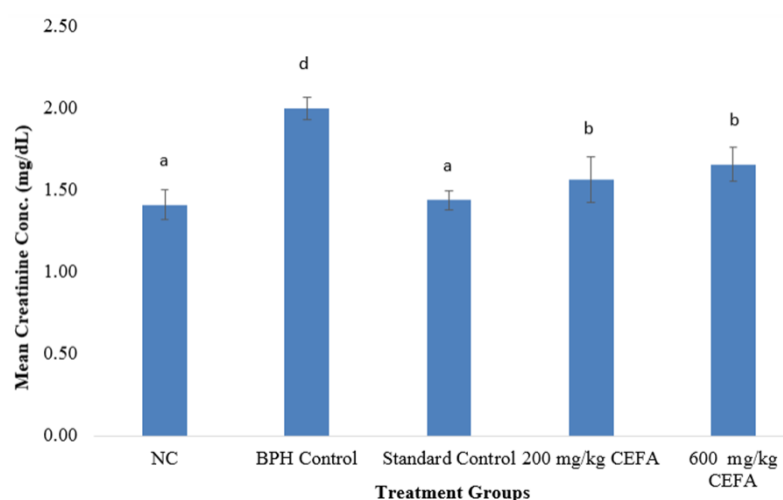

Fig. 7. Creatinine concentrations of $\mathrm{BPH}-$ induced rats treated with combined extract of $F$. africana and A. mauritianum leaves: NC - normal control, CEFA - combined extract of F. africana and A. mauritianum leaves. Each bar depicts the means \pm standard deviation $(n=6)$. Bars with differing superscripts are significantly different $(P<0.05)$

concentration in the BPH control rats, standard control rats and groups treated with low and high doses (200 and $600 \mathrm{mg} / \mathrm{kg}$ respectively) of CEFA was significantly $(p<0.05)$ higher compared to the NC. Also, the standard control group treated with Finasteride and $600 \mathrm{mg} / \mathrm{kg}$ b.w. of CEFA caused a significant $(p<0.05)$ decrease in the urea concentration when compared with the untreated BPH-induced control group. Treatment with $200 \mathrm{mg} / \mathrm{kg}$ of CEFA showed a significant $(p<0.05)$ increase in the urea concentration when compared with the standard control. As seen in Figure 7, the creatinine concentrations of the BPH-induced groups treated with 200 and $600 \mathrm{mg} / \mathrm{kg}$ of CEFA were significantly $(p<0.05)$ increased when compared to the NC. The creatinine concentration in the BPH-induced rats treated with a low dose $(200 \mathrm{mg} /$ $\mathrm{kg})$ of CEFA was significantly $(p<0.05)$ increased, while the one treated with a high dose $(600 \mathrm{mg} / \mathrm{kg})$ of CEFA was not significantly $(p>0.05)$ increased when compared to the BPH-induced control.

\section{Histopathological examination results}

Plates 1-5 show the effects of the combined extract of $F$. africana and A. mauritianum leaves (CEFA) on kidney histomorphology in BPH-induced albino rats. Sections of the kidney from the normal control rats showed normal renal histomorphology for laboratory rodents. Normal glomeruli $(\mathrm{G})$ were observed in the 
Uroko, R. I., Chukwu, C. N., Egba, S. I., Adamude, F. A., Ajuzie, J. C. (2020). Combined ethanol extract of Funtumia africana and Abutilon mauritianium leaves improves the lipid profile and kidney function indices of benign prostatic hyperplasia in rats. Acta Sci. Pol. Technol. Aliment., 19(4), 395-404. http://dx.doi.org/10.17306/J.AFS.2020.0813

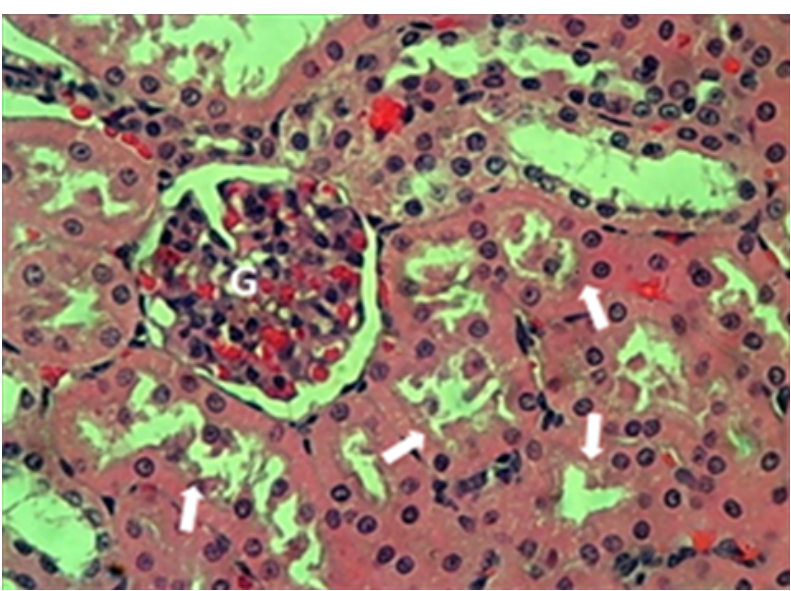

Plate 1. Histomorphology of kidney section from normal control rats that were not induced with benign prostatic hyperplasia $(\mathrm{BPH})$

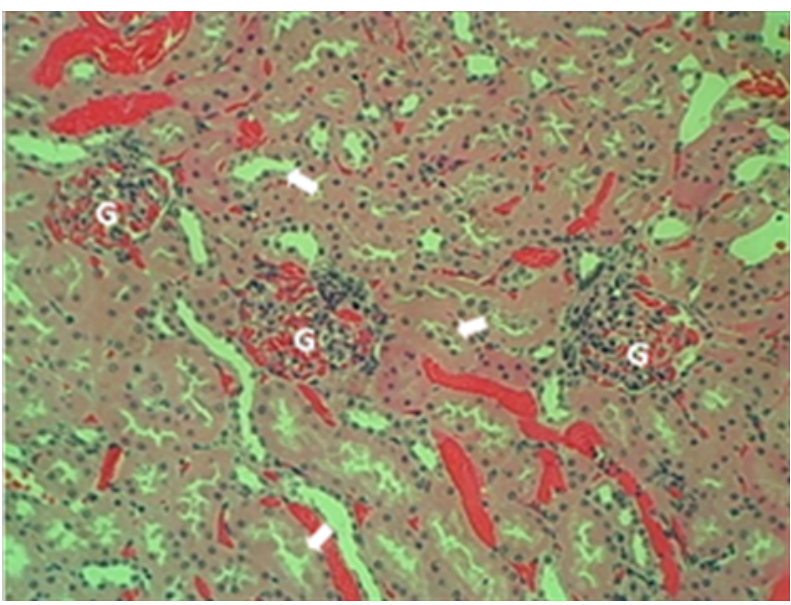

Plate 3. Histomorphology of kidney section from BPH-induced rats treated with $5 \mathrm{mg} / \mathrm{kg}$ of Finastride

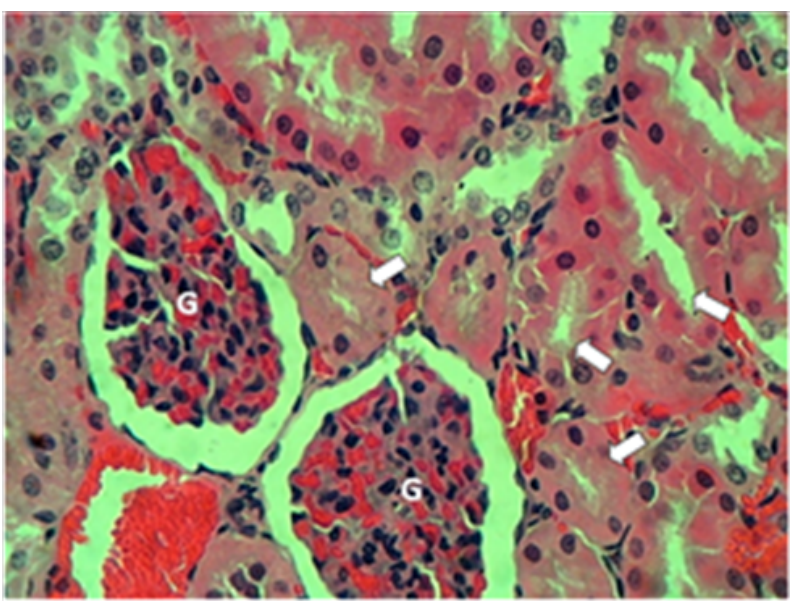

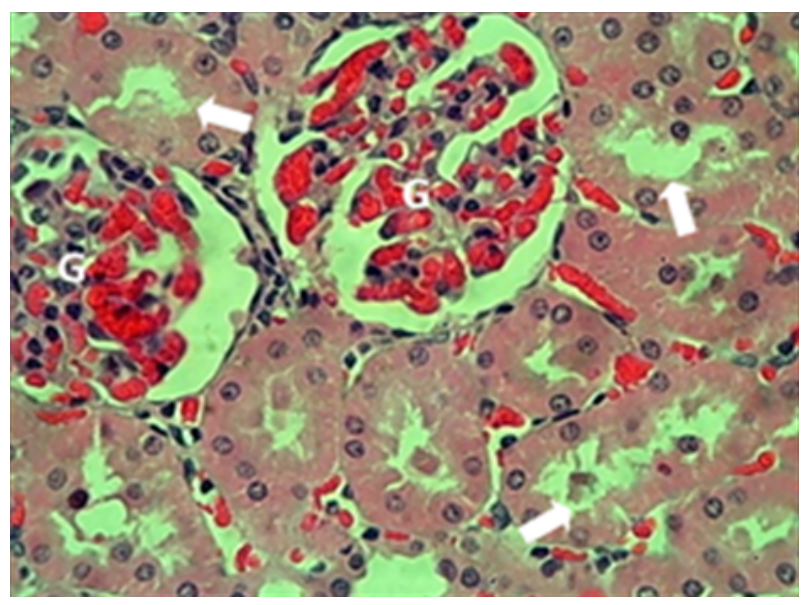

Plate 2. Histomorphology of kidney section from BPH-induced untreated rats

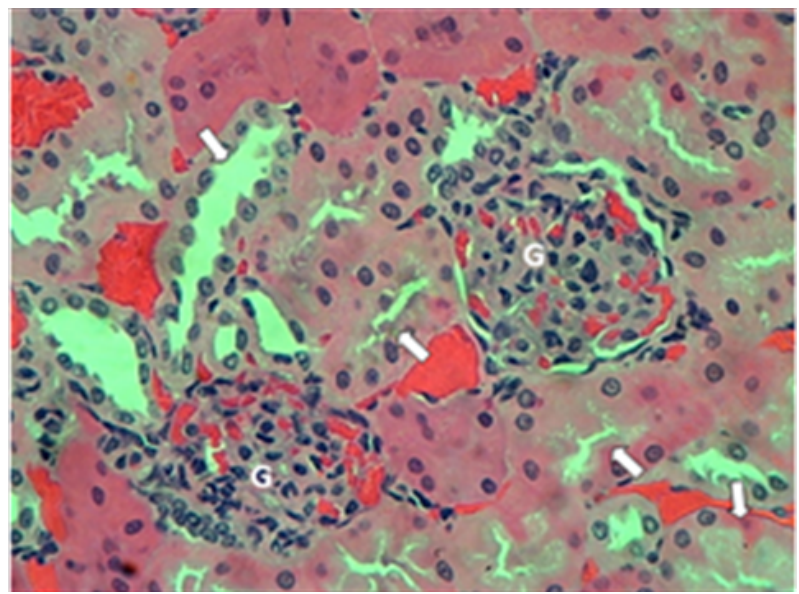

Plate 4. Histomorphology of kidney section from BPH-induced rats treated with $200 \mathrm{mg} / \mathrm{kg}$ of CEFA

cortex, surrounded by normal renal tubules (arrow). The renal tubules were also normal in the outer medulla and the inner medulla (plate 1). Similarly, the sections of kidneys from the $\mathrm{BPH}$-induced untreated rats (plate 2), BPH-induced rats treated with Finasteride (i.e. standard control) in plate 3, and BPH-induced rats treated with 200 and $600 \mathrm{mg} / \mathrm{kg}$ of CEFA (plates 4 and 5 respectively) showed normal kidney histomorphology of normal rodents.

Plate 5. Histomorphology of kidney section from BPH-induced rats treated with $600 \mathrm{mg} / \mathrm{kg}$ CEFA 


\section{DISCUSSION}

The acute toxicity (LD50) result of the combined extract on male albino rats showed no death or adverse reactions such as drowsiness or removal of hair, and suggests that the combined ethanol extract is relatively safe for consumption.

Triacylglycerols are the core components of body fat in humans (Lampe et al., 1983). The significant elevation in TAG concentration observed in group 2 (BPH-induced control) suggests that the impact of high toxicity may alter the TAG level, which may result in a buildup of lipid molecules in the arteries leading to atherosclerosis (Zhang et al., 2008). However, the significant decrease in groups 4 and 5 treated with 200 and $600 \mathrm{mg} / \mathrm{kg}$ of combined extract respectively, suggests no or less toxicity at such doses and so may have little or no impact on the heart when compared to group 2.

High-density lipoprotein - HDL is an essential marker for the transportation of lipids from exterior tissues to the kidney or liver. They can convey fat molecules out of the artery walls, diminish macrophage buildup, and aid in managing atherosclerosis (AUA, 2003). The substantial decline in HDL concentration detected in group 2 suggested a risk of cardiovascular disease when related to the normal control. However, the noteworthy surge in HDL concentration observed in groups 4 and 5 treated with 200 and 600 $\mathrm{mg} / \mathrm{kg}$ CEFA respectively, suggested a protective effect against hyperlipidemia and cardiovascular disease when compared to the BPH-induced control (group 2) that was not treated.

According to the result of total cholesterol on the effects of ethanol combined with the extract of $F$. africana and A. mauritianum leaves, it was observed that there was a significant increase in group 2 (BPH-induced control) when compared to the normal and standard controls respectively, illustrating that a high level of cholesterol amplifies and accelerates the risk of atherosclerosis in both middle and old age.

Low-density lipoprotein cholesterol (LDL) is an important marker for the risk of developing heart disease (Zhang et al., 2008). The non-significant elevation in LDL concentration in all groups (1-5) suggests no or low impact in the heart when compared to the normal, BPH-induced and standard controls.
Urea is a key metabolic product of biological pathways comprising ammonia, which is noxious to the body (D'Apolito et al., 2010). Therefore, its conveyance plays a vital part in nitrogen removal and osmotic homeostasis. The elevation in urea concentration caused by BPH was significantly lowered by the standard drug and $600 \mathrm{mg} / \mathrm{kg}$ of the combined extract. This is in line with the report of Asuk and Ugwu (2018) who reported a reduction in urea and creatinine levels in BPH-induced rats treated with Vernonia amygdalina. This suggests that a higher concentration of the combined extract and possibly longer-term administration may be more effective in ameliorating renal impairment in BPH patients.

Creatinine in serum is connected with a great risk of prostate cancer; especially in progressive cases where the risks of survival are low (Weinstein et al., 2009) and is also regarded as a veritable prostate cancer staging and predictive marker (Chiong et al., 2005). The rats treated with 200 and $600 \mathrm{mg} / \mathrm{kg}$ of CEFA showed an elevated level of creatinine when compared to the normal control, signifying impaired kidney function. However, the lower dose $(200 \mathrm{mg} / \mathrm{kg})$ of the combined extract caused a significant reduction in creatinine concentration when compared to the BPH-induced group. This result agrees with that of Reshma et al. (2014), who evaluated markers of renal dysfunction in prostate disorders and healthy controls. This suggests that lower doses of the combined extract may possess better nephroprotective potentials against testosterone propionate-induced benign prostatic hyperplasia in male albino rats.

According to the histomorphology of kidney sections of group 1 from renal histology, normal glomeruli in Bowman's capsule, bordered by a sea of renal tubules (arrow) were observed. Likewise, the kidney in group 2 showed its normal histology. This shows that the combined extract of $F$. africana and A. mauritanum leaves had no negative impact on the kidney tissues. However, the extract possesses the potential of ameliorating cardiovascular diseases and atherosclerosis and protecting against kidney damage.

\section{CONCLUSION}

This study has revealed that a combined ethanol extract of F. africana and Abutilon mauritianum leaves 
Uroko, R. I., Chukwu, C. N., Egba, S. I., Adamude, F. A., Ajuzie, J. C. (2020). Combined ethanol extract of Funtumia africana and Abutilon mauritianium leaves improves the lipid profile and kidney function indices of benign prostatic hyperplasia in rats. Acta Sci. Pol. Technol. Aliment., 19(4), 395-404. http://dx.doi.org/10.17306/J.AFS.2020.0813

is capable of averting the risks of hyperlipidaemia and renal injury. This is demonstrated by the significant positive modulation of HDL and TAG levels by CEFA in the treated rats. Also, the combined ethanol extract of $F$. africana and Abutilon mauritianum leaves attenuated the elevated renal indices in BPH-induced rats by significantly decreasing urea and creatinine levels after treatment; hence, indicating a renoprotective potential. Despite the effects of the combined ethanol extract of F. africana and Abutilon mauritianum on BPH-induced albino rats, the exact constituents responsible for these effects are not fully known, hence allowing for further studies.

\section{REFERENCES}

Allain, C. C., Poon, L. S., Chan, C. S., Richmond, W. F. P. C., Fu, P. C. (1974). Enzymatic determination of total serum cholesterol. Clin. Chem., 20(4), 470-475. https:// doi.org/10.1093/clinchem/20.4.470

Ashidi, J. S., Houghton, P. J., Hylands, P. J., Efferth, T. (2010). Ethnobotanical survey and cytotoxicity testing of plants of South-western Nigeria used to treat cancer, with isolation of cytotoxic constituents from Cajanus cajan Mill sp. leaves. J. Ethnopharm., 128(2), 501-512. https://doi.org/10.1016/j.jep.2010.01.009

Aslam, M. S., Ahmad, M. S., Mamat, A. S., Ahmad, M. Z., Salam, F. (2016). An update review on polyherbal formulation: A global perspective. Syst. Rev. Pharm., 7(1), $35-41$.

Asuk, A. A., Ugwu, M. N. (2018). Nephrotoprotective effect of Vernonia amygdalina (bitter leaf) extract on benign prostatic hyperplasia in adult male rats. Int. J. Biochem. Res. Rev., 22(4), 1-9. https://doi.org/10.9734/ IJBCRR/2018/42910

AUA Practice Guidelines Committee (2003). AUA guideline on management of benign prostatic hyperplasia (2003). Chapter 1: Diagnosis and treatment recommendations. J. Urol., 170(2), 530-547. https://doi.org/10.1097/01. ju.0000078083.38675.79

Beentje, H., Adamson, J., Bhanderi, D. (1994). Kenya trees, shrubs, and lianas. Nairobi, Kenya: National Museums of Kenya.

Burkill, H. M. (2004). The useful plants of west tropical Africa. Vol. 2. Families E-I. Kew, United Kingdom: Royal Botanic Gardens.

Chiong, E., Wong, A. F. W., Chan, Y. H., Chin, C. M. (2005). Review of clinical manifestations of biochemically-advanced prostate cancer cases. Asian J. Surgery, 28(3),
202-206. https://doi.org/10.1016/S1015-9584(09) 60344-4

Cowan, M. M. (1999). Plant products as antimicrobial agents. Clin. Microbiol. Rev., 12(4), 564-582. http://dx.doi.org/ 10.1128/CMR.12.4.564

D’Apolito, M., Du, X., Zong, H., Catucci, A., Maiuri, L., Trivisano, T., ..., Brownlee, M. (2010). Urea-induced ROS generation causes insulin resistance in mice with chronic renal failure. J. Clin. Inv., 120(1), 203-213. https:// doi.org/10.1172/jci37672

De Souza, P. A. R., Palumbo Jr, A., Alves, L. M., de Souza, V. P., Cabral, L. M., Fernandes, P. D., Nasciutti, L. E. (2011). Effects of a nanocomposite containing Orbignya speciosa lipophilic extract on Benign Prostatic Hyperplasia. J. Ethnopharm., 135(1), 135-146. https://doi. org/10.1016/j.jep.2011.03.003

Fawcett, J. K., Scott, J. (1960). A rapid and precise method for the determination of urea. J. Clin. Pathol., 13(2), 156-159. https://doi.org/10.1136\%2Fjcp.13.2.156

Foster, H. E., Barry, M. J., Dahm, P., Gandhi, M. C., Kaplan, S. A., Kohler, T. S., ..., Welliver, C. (2018). Surgical management of lower urinary tract symptoms attributed to benign prostatic hyperplasia: AUA guideline. J. Urol., 200(3), 612-619. https://doi.org/10.1016/j. juro.2018.05.048

Friedelwald, W. T., Levy, R. I., Fredrickson, D. S. (1972). Estimation of the concentration of low-density lipoprotein cholesterol in plasma, without use of the preparative ultracentrifuge. Clin. Chem., 18(6), 499-502.

Gupta, A., Gupta, S., Pavuk, M., Roehrborn, C. G. (2006). Anthropometric and metabolic factors and risk of benign prostatic hyperplasia: a prospective cohort study of Air Force veterans. Urology, 68(6), 1198-1205. https:// doi.org/10.1016/j.urology.2006.09.034

Henry, T. J. (1974). Clinical chemistry principles and techniques (2th ed.). New York: Harper and Row Publishers. https://doi.org/10.1093/clinchem/18.6.499

Institute of Laboratory Animal Resources (US). Committee on Care, Use of Laboratory Animals (1986). Guide for the care and use of laboratory animals (no. 86). US Department of Health and Human Services, Public Health Service, National Institutes of Health.

Lampe, M. A., Burlingame, A. L., Whitney, J., Williams, M. L., Brown, B. E., Roitman, E., Elias, P. M. (1983). Human stratum corneum lipids: characterization and regional variations. J. Lipid Res., 24(2), 120-130.

Lekili, M., Müezzinoğlu, T., Uyanık, B. S., Büyüksu, C. (2006). Serum lipid levels in benign prostatic hyperplasia. World J. Urol., 24(2), 210-213. https://dx.doi. org/10.1007/s00345-006-0062-6 
Lorke, D. (1983). A new approach to practical acute toxicity testing. Arch. Toxicol., 54(4), 275-287. https://doi. org/10.1007/BF01234480

Naslund, M. J., Gilsenan, A. W., Midkiff, K. D., Bown, A., Wolford, E. T., Wang, J. (2007). Prevalence of lower urinary tract symptoms and prostate enlargement in the primary care setting. Int. J. Clin. Pract., 61(9), 1437-1445. https://doi.org/10.1111/j.1742-1241.2007.01508.x

Odugbemi, T. O., Akinsulire, O. R., Aibinu, I. E., Fabeku, P. O. (2007). Medicinal plants useful for malaria therapy in Okeigbo, Ondo State, Southwest Nigeria. Afr. J. Trad. Compl. Altern. Med., 4(2), 191-198. https://dx.doi.org/ 10.4314\%2Fajtcam.v4i2.31207

Orwa, C., Mutua, A., Kindt, R., Jamnadass, R., Simons, A. (2009). Agroforestree Database: a tree reference and selection guide. Version 4. Agroforestree Database: a tree reference and selection guide. Version 4.

Parasuraman, S., Thing, G. S., Dhanaraj, S. A. (2014). Polyherbal formulation: Concept of ayurveda. Pharm. Rev., 8(16),73.https://doi.org/10.4103\%2F0973-7847.134229

Park, E., Lee, M. Y., Jeon, W. Y., Lee, N., Seo, C. S., Shin, H. K. (2016). Inhibitory effect of yongdamsagan-tang water extract, a traditional herbal formula, on testosterone-induced benign prostatic hyperplasia in rats. Evid.-Based Compl. Altern. Med. ID 1428923. https://doi. org/10.1155/2016/1428923

Parsons, J. K., Bergstrom, J., Barrett-Connor, E. (2008). Lipids, lipoproteins and the risk of benign prostatic hyperplasia in community-dwelling men. BJU Int., 101(3), 313-318. https://orcid.org/10.1111/j.1464-410X.2007. 07332.x

Parsons, J. K., Kashefi, C. (2008). Physical activity, benign prostatic hyperplasia, and lower urinary tract symptoms. Eur. Urol., 53(6), 1228-1235. https://doi.org/10.1016/ j.eururo.2008.02.019

Reshma, K., Kuthethur, S., Manjerekar, P., Gopal, M. (2014). Evaluation of biochemical markers of renal dysfunction in prostate disorders and healthy controls.
Int. J. Biochem. Adv. Res., 5(9), 415-417. https://doi. org/10.7439/ijbar.v5i9.835

Rule, A. D., Jacobson, D. J., Roberts, R. O., Girman, C. J., McGree, M. E., Lieber, M. M., Jacobsen, S. J. (2005). The association between benign prostatic hyperplasia and chronic kidney disease in community-dwelling men. Kidney Int., 67(6), 2376-2382. https://doi.org/10.1111/ j.1523-1755.2005.00344.x

Sharma, M., Chadha, R., Dhingra, N. (2017). Phytotherapeutic agents for benign prostatic hyperplasia: an overview. Mini-Rev. Med. Chem., 17(14), 1346-1363. https://doi.org/10.2174/1389557516666160621103817

Sun, C., Peng, Y., Wu, Y., Zhang, Y., Li, X. (2020). The effect of Metapanax delavayi leaf extract on testosterone-induced benign prostatic hyperplasia in rats. J. Funct. Foods, 66, 103797. https://doi.org/10.1016/j.jff. 2020.103797

Weinstein, S. J., Mackrain, K., Stolzenberg-Solomon, R. Z., Selhub, J., Virtamo, J., Albanes, D. (2009). Serum creatinine and prostate cancer risk in a prospective study. Cancer Epid. Prev. Biomar., 18(10), 2643-2649. https:// doi.org/10.1158/1055-9965.EPI-09-0322

Wu, X., Gu, Y., Li, L. (2017). The anti-hyperplasia, antioxidative and anti-inflammatory properties of Qing Ye Dan and swertiamarin in testosterone-induced benign prostatic hyperplasia in rats. Toxicol. Lett., 265, 9-16. https://doi.org/10.1016/j.toxlet.2016.11.011

Zhang, D. W., Garuti, R., Tang, W. J., Cohen, J. C., Hobbs, H. H. (2008). Structural requirements for PCSK9-mediated degradation of the low-density lipoprotein receptor. Proc. Nat. Acad. Sci., 105(35), 13045-50. https://dx.doi. org/10.1073\%2Fpnas.0806312105

Zucchetto, A., Tavani, A., Dal Maso, L., Gallus, S., Negri, E., Talamini, R., ..., La Vecchia, C. (2005). History of weight and obesity through life and risk of benign prostatic hyperplasia. Int. J. Obes., 29(7), 798-803. https:// doi.org/10.1038/sj.ijo.0802979 